- Bisphosphonates are commonly prescribed drugs and their use is increasingly being associated with osteonecrosis of the jaws.

- Associated factors in the development of osteonecrosis include poor dental health, odontogenic infection and invasive dental treatment.

- The dental management of patients with a history of bisphosphonate treatment is based around prevention and minimally traumatic treatment.

\title{
Bisphosphonate osteonecrosis of the jaws; an increasing problem for the dental practitioner
}

\author{
N. M. H. McLeod, ${ }^{1}$ B. J. B. Davies ${ }^{2}$ and P. A. Brennan ${ }^{3}$
}

\begin{abstract}
Osteonecrosis of the jaws is an increasingly recognised complication of bisphosphonate therapy. Although this has generated a large amount of literature in the last few years, it is difficult to know how the complications associated with bisphosphonates are impacting on general dental practitioners (GDPs). Bisphosphonates are commonly prescribed in the management of osteoporosis, hypercalcemia and multiple myeloma. The risk of osteonecrosis in patients taking bisphosphonates is low but difficult to quantify. The risk associated with oral therapy is in the order of $0.01 \%$ although with parenteral therapy it may be as high as 10\%. Associated factors in the development of osteonecrosis include poor dental health, odontogenic infection and invasive dental treatment. Guidelines on managing patients who are currently taking or have previously taken bisphosphonates have not yet been published in the UK. The management of patients relies on existing experience in managing patients with apparently similar conditions such as osteoradionecrosis. Most GDPs do not routinely make specific efforts to identify patients who have taken bisphosphonates, and as patients may be poor at providing such information voluntarily, it is likely that many patients are currently not identified when they attend general dental practice. The dental management of patients with a history of bisphosphonate treatment is based around prevention and minimally traumatic treatment. Failure to recognise these patients and manage them appropriately could contribute to the development of osteonecrosis, which can be very difficult to manage.
\end{abstract}

\section{BISPHOSPHONATES}

Bisphosphonates are pyrophosphate analogues, which share a common phosphorous-carbon-phosphorous chemical core, and inhibit the resorption of bone. They are principally used in the treatment of osteoporosis, Paget's disease, multiple myeloma, bony metastatic lesions and hypercalcemia of malignancy. These compounds have been synthesised since

"Specialist Registrar in Oral \& Maxillofacial Surgery ${ }^{2}$ Specialist Registrar in Surgical Dentistry, ${ }^{3}$ Consultant in Oral \&t Maxillofacial Surgery and Professor of Surgery, Department of Oral \& Maxillofacial Surgery, Queen Alexandra Hospital, Portsmouth, BN11 4LJ ${ }^{*}$ Correspondence to: Mr Niall McLeod Email:niall_mcleod@yahoo.co.uk

\section{Refereed Paper}

Accepted 12 July 2007

DOI: $10.1038 /$ bdj.2007.1065

${ }^{\circ}$ British Dental Journal 2007; 203: 641-644 the nineteenth century but it is only in the second half of the twentieth century that their in vitro ability to inhibit the precipitation of calcium phosphate was applied clinically. In vivo they act both by inhibiting the precipitation of hydroxyapatite crystals and by direct action on osteoclasts. ${ }^{1,2}$

There are two classes of bisphosphonates which have different mechanisms of action on osteoclasts based on the presence or absence of a nitrogen side chain on the pyrophosphate group (Table 1). Non-nitrogen containing bisphosphonates are taken up by the osteoclast and antagonise the cellular energy pathways leading to cell apoptosis. They therefore decrease bone breakdown by reducing osteoclast cell numbers. Nitrogen containing bisphosphonates have a more complex pathway of action where they inhibit the HMG-CoA reductase pathway which affects the osteoclastogenesis, apoptosis and cytoskeletal dynamics, resulting in loss of adherence of osteoclasts to the surface of bone. ${ }^{1}$ Zoledronate has also been shown to inhibit human endothelial cell proliferation and to modulate endothelial cell adhesion and migration. ${ }^{3}$ The antitumour effect of bisphosphonates is thought to be due to induction of tumour cell apoptosis, and inhibition of tumour cell adhesion and invasion. ${ }^{4}$ Absorption of bisphosphonates from the gastrointestinal tract is variable, but generally poor with only 1-5\% of ingested preparation becoming bioavailable. The bisphosphonates are excreted from the body unchanged, via the kidneys. About 50\% of the absorbed dose is excreted whilst the remainder is absorbed onto the surface of bone, for 


\begin{tabular}{|c|c|c|c|c|}
\hline Drug name & Trade name & $\begin{array}{l}\text { Route of } \\
\text { administration }\end{array}$ & $\begin{array}{l}\text { Nitrogen } \\
\text { containing }\end{array}$ & $\begin{array}{l}\text { Number of } \\
\text { adverse events } \\
\text { reported }\end{array}$ \\
\hline Disodium etidronate & Didronel & Oral & No & 23 \\
\hline Tiludronic acid & Skelid & Oral & No & 0 \\
\hline Sodium clodronate & Bonefos, Loron & $\begin{array}{l}\text { Oral / } \\
\text { Parenteral }\end{array}$ & No & 3 \\
\hline Disodium pamidronate & Aredia & Parenteral & Yes & 20 \\
\hline Alendronic acid & Fosamax & Oral & Yes & 121 \\
\hline Risedronate sodium & Actonel & Oral & Yes & 36 \\
\hline Ibandronic acid & Bondronat & $\begin{array}{l}\text { Oral / } \\
\text { Parenteral }\end{array}$ & Yes & 9 \\
\hline Zoledronic acid & Zometa & Parenteral & Yes & 102 \\
\hline
\end{tabular}

Table 2 Predisposing factors for osteonecrosis of the jaws

\begin{tabular}{l|l}
\hline Systemic factors & Local factors \\
\hline Haemoglobinopathies & Sepsis (apical or periodontal) \\
\hline Lymphoproliferative disorders & Trauma (surgical or local) \\
\hline Paget's disease & Radiotherapy \\
\hline Phosphorous exposure & \\
\hline Bisphosphonates & \\
\hline
\end{tabular}

which it has a high affınity. Oral and parenteral preparations are available with differing biovailabilities and potencies. Generally the nitrogen containing preparations are more potent (Table 1) and are retained longer in bone.

The duration of effect of bisphosphonates extends far beyond the duration of treatment. The effect of aledronate may be evident for more than five years after discontinuation of treatment and zoledronate has been shown to produce a sustained reduction in bone turnover for 12 months following administration of a single dose. ${ }^{5,6}$

\section{OSTEONECROSIS OF THE JAWS}

Osteonecrosis means the process of bone death. Osteonecrosis of the jaws may be associated with a number of different predisposing conditions (Table 2), and its pathophysiology varies with the predisposing factors. Radiotherapy is associated with endarteritis obliterans and consequently avascular necrosis of the fracture may be the presenting feature. In the early stages there may be no obvious radiological changes but later on there will be evidence of bone mottling and sequestrum formation similar to osteomyelitis. ${ }^{8}$

\section{Bisphosphonate associated osteonecrosis of the jaws}

Ulceration of the oral mucosa as a complication of oral bisphosphonate therapy was described in 1999 but this was thought to be due to direct mucosal injury. ${ }^{9}$ Osteonecrosis associated with the use of bisphosphonates was first described by Marx in 2003, ${ }^{10}$ since which there have been a multitude of case series published. ${ }^{4}$

The link between osteonecrosis and dental treatment is deduced from the data that between 33 and $86 \%$ of reported cases had undergone surgical treatment in the period before their diagnosis and the fact that the area of osteonecrosis was co-incident with the area of treatment. ${ }^{2}$

Why bisphosphonates have a predilection for causing osteonecrosis in the jaws is not yet fully understood. It is thought to be related to the jaws being repeatedly traumatised by mastication and their exposure to the oral environment and commensal micro-organisms. ${ }^{11}$

Many cases, however, arise apparently spontaneously (perhaps as a result of innocuous trauma) and the dentist therefore must be vigilant to the potential diagnosis when examining patients with symptoms and signs which would be consistent with bisphosphonate osteonecrosis (BON).

BON affects the mandible to maxilla in a ratio of approximately $2: 1$, and not uncommonly both are affected. ${ }^{12}$ Multifocal involvement has been described, mostly in the maxilla. ${ }^{4}$ The maxilla is therefore affected more commonly than in osteoradionecrosis, as would be expected from the understanding that radiotherapy has a direct action on bone, and the mandible is more commonly irradiated than the maxilla, whereas bisphosphonates have a systemic effect.

There is as yet no agreed consensus on a method of staging and management guidelines for BON but those suggested by Ruggiero et al. are a reasonable approach until further evidence is available. ${ }^{13}$ The potential difficulties in creating larger problem through injudicious 
treatment make it sensible to suggest that cases should be managed by oral or maxillofacial surgeons with an interest in the condition.

Not surprisingly the wide reporting of this problem has led to a number of high profile advertisements from medicolegal experts in the United States offering to take on cases of victims against the drug companies (Internet search, January 2007, search terms: bisphosphonate, osteonecrosis, law). It is therefore quite possible that there could be similar cases made against the prescribing physicians and dental surgeons treating such patients in the United Kingdom.

\section{The scale of the potential problem}

Bisphosphonates are commonly prescribed medications but there are no clear figures on the incidence of BON. No cases of BON were described in the clinical trials of bisphosphonates; however, this may indicate inadequate periods of follow up or simply failure to recognise the problem. Bamias et al. found that 10\% of patients with multiple myeloma and $3 \%$ of patients with breast cancer treated with intravenous bisphosphonates developed osteonecrosis. ${ }^{14}$ One report has also suggested an increased risk where patients have received two different parenteral preparations sequentially. ${ }^{15}$

Although oral bisphosphonates are the most commonly prescribed form of these drugs, the incidence of BON associated with their use represent only approximately $11 \%$ of reported cases of BON. ${ }^{16}$ An expert panel from the American Dental Association ${ }^{17}$ has estimated that the risk associated with oral bisphosphonates is in the order of 0.7 per 100,000 prescribed patient years, based on data reported by pharmaceutical companies. Data from Australia suggest an incidence of $0.01 \%$ to $0.04 \%$, increasing to $0.09 \%$ to $0.34 \%$ in patients having dental extractions. ${ }^{18}$

Long term longitudinal studies will be required to elucidate more accurately the incidence, and whether specific bisphosphonates carry different risks. However, the sheer number of patients being prescribed bisphosphonates suggest that this is likely to be a significant problem.

Within the catchment area of our hospital, 160,000 prescriptions have been issued for bisphosphonates in the last five years in primary and secondary care. Two hundred and eighty patients

\begin{tabular}{l|l}
\hline \multicolumn{2}{|l}{ Table 3 Summary of expert panel guidelines on dental management of patients } \\
\hline & Before prescribing \\
\hline Information for prescriber & Consider and inform patient of risk of BON \\
\hline & Advise patient to seek dental assessment and treatment \\
\hline Information for dentist & Full dental examination \\
\hline & Complete all necessary dental treatment and preventative advice \\
\hline & After prescribing \\
\hline Information for prescriber & Advise regular dental attendance \\
\hline & Refer for assessment patents with oral symptoms consistent with BON \\
\hline Information for dentist & Non-Surgical treatment where possible \\
\hline & Chlorhexidene mouthwash pre-operatively and until all wounds have healed \\
\hline & Consider prophylactic antibiotics pre and post operatively \\
\hline
\end{tabular}

have received parenteral bisphosphonates since 2002. Although it is not possible to state how many patients are on oral bisphosphonates from the number of prescriptions issued, assuming every patient has received a prescription for every month since first prescribed, this suggests that at least 3,850 patients have received oral bisphosphonates. This may be a substantial underestimate.

The medical literature contains case reports and series describing over 350 cases of BON, however, to date, none have included cases from the United Kingdom. ${ }^{2}$

In the United Kingdom adverse events following administration of prescribed drugs should be reported to the Medicines and Healthcare products Regulatory Agency (MHRA). One hundred and fiftyeight reports of bone disorders (which includes seven reports of osteomyelitis and 58 of osteonecrosis), 13 reports of jaw disorders including pain and fracture, and 143 reports of other oral disorders including pain, ulceration and dental extractions have been recorded by the MHRA up to May 2006. ${ }^{19}$ This constitutes some $8 \%$ of adverse incidents reported for bisphosphonate class drugs (Table 1).

\section{GDP knowledge of bisphosphonates}

To obtain some information on the current knowledge of GDPs regarding bisphosphonates, we performed a postal survey of local GDPs, which asked whether they specifically asked about bisphosphonates as part of patients' medical history and whether they recommended antibiotic prophylaxis in such patients. Thirty-one replies were received from the 60 practices surveyed (52\%).
Five out of 31 (16\%) enquired specifically about bisphosphonates as part of the medical history. Self reporting of medication is poor, particularly for intermittent medication, and likely to be worse for medication which may only have been prescribed once as may be the case with parenteral bisphosphonates. The potentially catastrophic consequences of developing established BON are such that we feel that general dental practitioners should ask specifically about these drugs as part of their medical history for new patients and enquire again with returning patients. ${ }^{20}$

The effects of bisphosphonates is known to last a long time with most cases of BON associated with oral bisphosphonates presenting after 36 months and most associated with parenteral bisphosphonates presenting after 13 months. Patients with a past history of bisphosphonate therapy should therefore be managed in the same manner as patients on current therapy. ${ }^{12}$

\section{Recommendations for managing patients} with a history of bisphosphonate therapy Whilst ultimately the incidence of BON is not known, what is clearly established is its association with poor dental health.

There are at present no consensus guidelines from British institutions on how to manage patients who are currently or have previously been prescribed bisphosphonates. The American Dental Association $^{17}$ and the Australian Dental Association ${ }^{18}$ have produced guidelines regarding the dental management of patients prescribed bisphosphonates. They all state that there is currently no 
evidence basis for the guidelines and they are based on the recommendations of panels of experts.

Recommendations have also been published on the use of bisphosphonates in osteoporosis and multiple myeloma on the basis of the risk of developing osteonecrosis. ${ }^{21,22}$ A summary of the available guidelines is presented in Table 3.

The general consensus is that patients should, where possible, undergo a dental assessment, and any necessary treatment should be undertaken, before commencing on bisphosphonates. The risk of BON should be considered when discussing the advantages and disadvantages of bisphosphonate therapy. There is currently no evidence to suggest that there is any benefit in stopping bisphosphonate therapy for a period if dental treatment becomes necessary, or that there is a safe time period after bisphosphonate treatment, when the risk of BON reduces.

The emphasis thereafter is on prevention, including regular dental assessment and oral hygiene instruction. Treatment, where necessary, should avoid extractions and surgery to the gingivae.

Where required, extraction and other procedures should involve a conservative surgical technique and primary soft tissue closure where possible. Chlorhexidene mouthwash is recommended before treatment and afterwards for up to two months.

Antibiotics are reserved for cases where the treatment involves significant manipulation of alveolar bone and the ADA panel recommends antibiotics for two days before and 14 days after treatment, depending on the presence of other risk factors and planned surgery.
Recommended antibiotics are amoxicillin + /- metronidazole, or clindamycin or azithromycin where penicillin allergic.

Only one out of 31 (3\%) GDPs we surveyed recommended antibiotic prophylaxis in patients who were taking bisphosphonates. In the absence of evidence based guidelines, particularly in the UK, it would be unreasonable to be critical of the current practice of general dental practitioners in not prescribing antibiotic prophylaxis for patients on bisphosphonates, however, it does highlight a need for guidelines to be established and circulated by the equivalent UK bodies.

It may be helpful if a system of patient cards, similar to those used for patients prescribed steroids, was instituted. Patients prescribed bisphosphonates could be given a card with details of their treatment to give to any treating dentist. Signs and symptoms of BON may also be listed for patients to look out for.

1. Fleisch H. Bisphosphonates: mechanisms of Action. Endocr Rev 2002; 19: 80-100.

2. Woo S, Hellstein J W, Kalmar J R. Systematic review. bisphosphonates and osteonecrosis of the jaws. Ann Intern Med 2006; 144: 753-761.

3. Wood J, Bonjean K, Reutz S et al. Novel antiangiogenic effects of the bisphosphonate compound zoledronic acid. J Pharmacol Exp Ther 2002; 302: 1055-1061.

4. Santini D, Vespasiani Gentilucci U, Vincenzi B et al. The antineoplastic role of bisphosphonates: from basic research to clinical evidence. Ann Oncol 2003; 14: 1468-1476.

5. Ensrud K E, Barrett-Connor E L, Schwartz A et al. Randomized trial of effect of aledronate continuation versus discontinuation in women with low BMD: results from the Fracture Intervention Trial long term extension. J Bone Miner Res 2004; 19: 1259-1269

6. Reis I R, Brown J P, Burckhardt P et al. Intravenous zoledronic acid in postmenopausal women with low bone mineral density. N Engl J Med 2002: 346: 653-661.

7. Hellstein J W, Marek C L. Bisphosphonate osteochemonecrosis (bis-phossy jaw): is this phossy jaw of the 21st century? J Oral Maxillofac Surg 2005; 63: 682-689.

8. Chiandussi S, Biasotto M, Dore F et al. Clinical and diagnostic imaging of bisphosphonate-associated osteonecrosis of the jaws. Dentomaxillofac Radiol 2006; 35: 236-243.

9. Demerjian N, Bolla G, Spreux A. Severe oral ulceration induced by aledronate. Clin Rheumatol 1999; 18: 349-350.

10. Marx R E. Pamidronate (Aredia) and Zoledronate (Zometa) induced avascular necrosis of the jaws: a growing epidemic. J Oral Maxillofac Surg 2003; 61: 115-118.

11. Leite A F, Figuieredo PT, Melo N S et al. Bisphosphonate-associated osteonecrosis of the jaws. Report of a case and literature review Oral Surg Oral Med Oral Pathol Oral Radiol Endod 2006; 102: 14-21.

12. Marx R E, Sawatari Y, Fortin M, Broumand $\mathrm{V}$. Bisphosphonate-induced exposed bone (osteonecrosis/osteopetrosis) of the jaws: risk factors, recognition, prevention and treatment. J Oral Maxillofac Surg 2005; 63: 1567-1575.

13. Ruggiero S L, Fantasia J, Carlson E. Bisphosphonate-related osteonecrosis of the jaw: background and guidelines for diagnosis, staging and management. Oral Surg Oral Med Oral Pathol Oral Radiol Endod 2006; 102: 433-441.

14. Bamias A, Kastritis E, Bamia C et al. Osteonecrosis of the jaw in cancer after bisphosphonates: incidence and risk factors. J Clin Oncol 2005; 23: 8580-8587.

15. Badros A, Weikel D, Salama A et al. Osteonecrosis of the jaws in Multiple Myeloma patients: clinical features and risk factors. J Clin Oncol 2006; 24: 945-952.

16. Ruggiero S L, Mehrotra B, Rosenberg T J, Engroff $S \mathrm{~L}$. Osteonecrosis of the jaws associated with the use of bisphosphonates: a review of 63 cases. J Oral Maxillofac Surg 2004; 62: 527-534.

17. American Dental Association council on Scientific Affairs. Dental management of patients receiving oral bisphosphonate therapy. J Am Dent Assoc 2006; 137: 1144-1150.

18. Sambrook P, Olver I, Goss A. Bisphosphonates and osteonecrosis of the jaws. Aust Fam Physician 2006; 35: 801-803.

19. www.mhra.gov.uk. Accessed January 2007.

20. Cheng A, Mavrokokki A, Carter G et al. The dental implications of bisphosphonates and bone disease. Aust Dent J 2005; 50(Suppl) 2: S4-S13.

21. Capsoni F, Longhi M, Weinstein R. Bisphosphonateassociated osteonecrosis of the jaw: the rheumatologist's role. Arthritis Res Ther 2006; 8: 219.

22. Lacy M Q, Dispenzieri A, Gertz M A et al. Mayo Clinic consensus statement for the use of bisphosphonates in multiple myeloma. Mayo Clin Proc 2006; 81: 1047-1053. 